\title{
Influence and Linkage of Buyers'-Suppliers' Attitude Towards E-Procurement Adoption in Developing Countries: Tanzania Context
}

\author{
Deus N. Shatta ${ }^{1 *}$, France A. Shayo ${ }^{2}$ and John N. Layaa ${ }^{3}$ \\ Corresponding e-mail: \\ ${ }^{1} \mathrm{Ph} . \mathrm{D}$ candidate at Open University of Tanzania \\ ${ }^{2} \mathrm{Ph}$.D Lecturer at Open University of Tanzania \\ ${ }^{3}$ Ph.D Lecturer at National Institute of Transport
}

\section{ARTICLE INFO}

Keywords:

E-Procurement

Adoption

Attitude

Buyer

Supplier

\begin{abstract}
The objective of this study was to fill the knowledge gap through analyzing the influence and linkage of buyers'-suppliers' attitude towards e-procurement adoption in developing countries, Tanzania in particular. This study was guided by Unified Theory of Acceptance and Use of Technology and the Technology, Organization and Environment model. The study adopted crosssectional survey research design. The study also used non-probability (purposive) sampling and probability (stratified) sampling techniques. Sample size was 157 . Questionnaires and documentary review were used for data collection. The collected data were analysed by using Partial Least Squares Structural Equation Modelling with the help of SmartPLS 3 software. Findings reveal that buyers'-suppliers' attitude has direct influence and links the performance expectancy, relative advantage and legal framework towards e-procurement adoption in public sector. The findings and recommendations of this study are anticipated to improve the adoption of e-procurement in developing countries, Tanzania in particular.
\end{abstract}

\section{Introduction}

\subsection{Overview and Problem Setting}

Jeptoo and Karanja (2017) emphasize that the public sector organizations which adopted eprocurement system have been able to increase efficiency, transparency, save operations/administration cost and reduce corruption in public services. Despite the benefits that could be achieved from a successful e-procurement implementation in the public sector and its positive performance, some buyers and suppliers have been waving to adopt eprocurement system due to various insights (Basheka et al., 2012; Mujtaba, 2014; Latif, 2014). For example, 326 (30.9 per cent) of the trained suppliers for piloting the Tanzania National eProcurement System (TANePS) adoption in the country were reluctant to register in system due to diverse insights on the new public procurement system (URT, 2018). Likewise, 63.4 percent of the selected procuring entities for piloting TANePS were found not implementing the system during the financial year 2018/2019 regardless of the trainings attended by procurement officers from selected entities (URT, 2019). In addition, there was drop out of the registered suppliers in TANePS by 1.2 per cent during the financial year 2018/2019 (URT, 2018; URT, 2019).

* Corresponding Author E-Mail Address: deusshatta@gmail.com 
To amplify the rate of adoption, massive training was conducted by Public Procurement Regulatory Authority (PPRA) during the financial year 2018/2019 and 2019/2020 respectively to create awareness of the performance and benefits of the system to the procurement officers from all procuring entities in country (Shilla, 2019). However, the massive training evaluation report revealed that 60 per cent of the trainees from procuring entities said time of training them was not enough to understand the performance of the system (Shilla, 2019). In addition, the massive training did not involve suppliers, service providers and contractors because it was assumed that they can register themselves in TANePS without any training (Shilla, 2019).

On the other hand, this study is supporting the argument that for any e-procurement initiative to be successful, early supplier and buyer involvement in training with regard to benefits and performance of the new system have to be considered in order to avoid diverse insights of the buyers and suppliers on the new public procurement system (Mose et al., 2013). The diverse nature of the insights on e-procurement adoption among buyers and suppliers has attracted a number of researchers who want to understand the reasons for this diversity.

However, most of the studies related to e-procurement adoption in developing countries (Watuleke, 2017; Ibem et al., 2016; Azanlerigu \& Akay, 2015; Ombat, 2015; Shale, 2014;Mgidlana, 2013; Kassim \& Hussin, 2013), Tanzania in particular (Malekia, 2018 and Suleiman, 2015) have diverse focuses on the unit of analysis. These studies have focused either on buyers' perspectives or suppliers' perspectives and the focus on both buyers' and suppliers' perspectives has been inadequately considered.

Taking into account those differences in the existing literature, combined with diverse insights of buyers and suppliers during piloting the new public procurement system in the country, this study was inspired to be conducted in order to bring fresh views on critical success factors influencing TANePS adoption in public sector whose rate of implementation in all procuring entities is not exciting. This study is also supporting the argument that success of any eprocurement implementation depends on determination and assessment of the critical success factors which, in turn, influence the adoption of e-procurement system (Mose et al., 2013).

One of the critical success factors for e-procurement adoption in public sector is legal framework as cited in one of the empirical studies that many countries around the world are improving their public procurement systems both in terms of their legal frameworks and their practical procedures towards e-procurement adoption (Schooner et al., 2008). Other critical success factors include performance expectancy of the system and its benefits (relative advantages) as cited in literature that e-procurement system has gained a reputation of being one of the most effective way in attaining sustainable procurement, efficiency and transparency in terms of its performance and benefits it brings to the public procurement processes (URT, 2016; Iles, 2017).

\subsection{Model Construct and Hypotheses}

The study employed one critical success factor influencing adoption of new technology from UTAUT (performance expectancy) and three critical success factors influencing adoption of new technology from TOE model (legal framework, relative advantage (perceived benefits) and attitude). The study also involved four endogenous constructs and one exogenous construct. Endogenous constructs included performance expectancy, relative advantage (perceived benefits), attitude and TANePS adoption. The exogenous construct was legal framework because this study supports the argument that countries are increasingly improving their public procurement systems first (amending legal frameworks first) and then their practical procedures towards e-procurement adoption in public sector (Schooner et al., 2008). That means, legal framework is regarded as dominant critical success factor which influences other critical success factors towards e-procurement adoption in public sector. In addition, performance expectancy of the system determines the benefits (relative advantage) of the system because this study supports the argument that e-procurement system has gained a reputation of being one of the most 
effective way in attaining sustainable procurement, efficiency and transparency in terms of its performance and benefits it brings to the public procurement processes (URT, 2016; Iles, 2017). Lastly, change of attitude of buyers and suppliers depends on understanding of the legal framework of the particular country, performance and relative advantage of the system because this study supports the argument that despite the performance and benefits of e-procurement, some stakeholders do hesitate to use the system due to diverse perceptions (Latif, 2014). Whether the assertions are valid or not valid in relation to paradigm shift to e-procurement adoption in Tanzanian public sector, it was something valuable and worth researching. Based on that, a number of concepts were conceptualised as depicted in the conceptual model Figure 1.
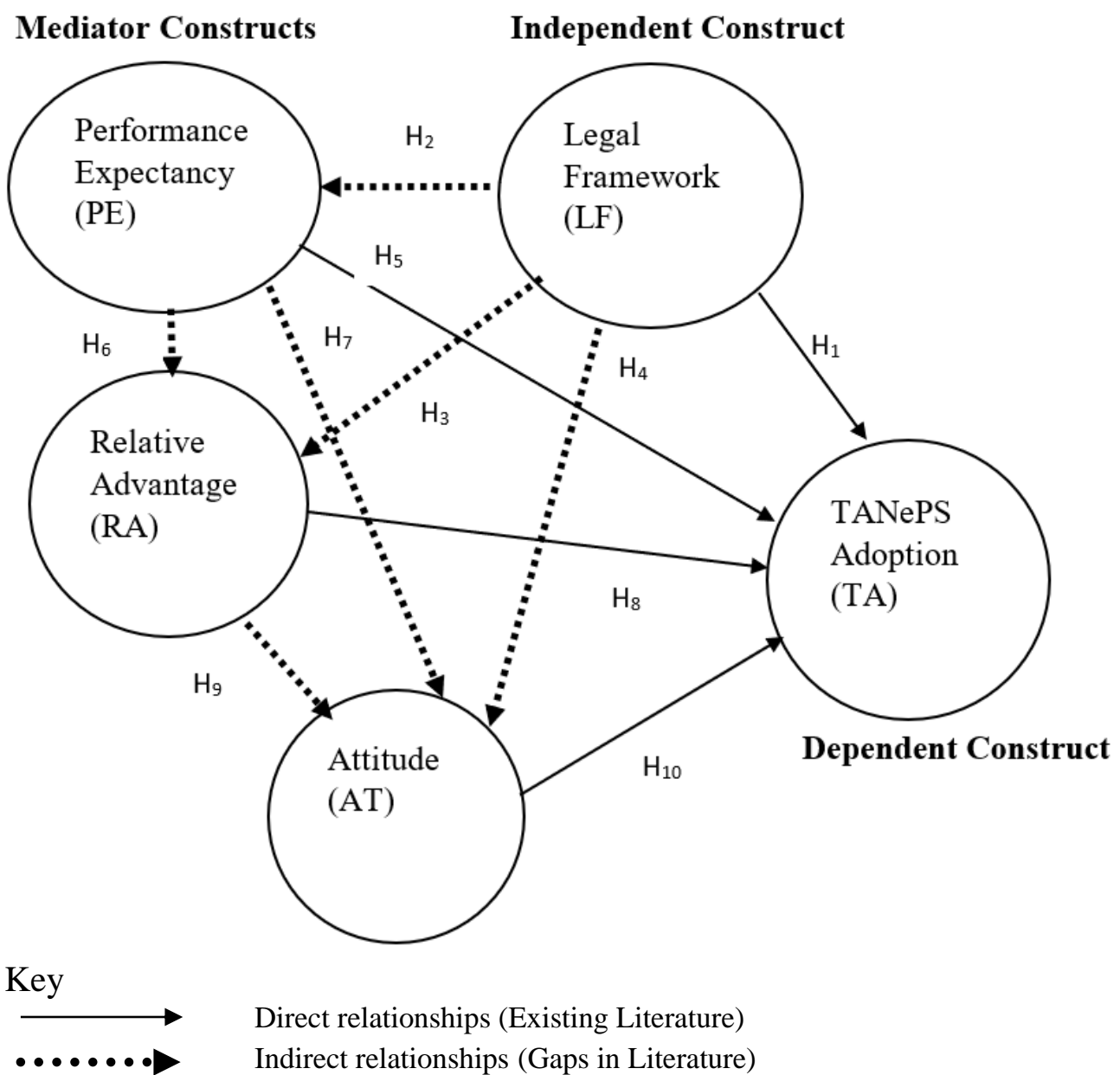

Figure 1. Conceptual Model; Source: Conceptualized from Literature, 2020

In order to operationalise the concepts in the model, the following hypotheses were tested:

$\mathrm{H}_{1 \mathrm{a}}$ : Legal framework (LF) positively and directly influences TANePS adoption in the public sector

$\mathrm{H}_{1 b}$ : In the presence of Performance Expectancy (PE), Legal framework (LF) positively and indirectly influences TANePS adoption in the public sector.

$\mathrm{H}_{1 \mathrm{c}}$ : In the presence of Relative Advantages (RA), Legal framework (LF) positively and indirectly influences TANePS adoption in the public sector.

$\mathrm{H}_{1 \mathrm{~d}}$ : In the presence of Attitude (AT), Legal framework (LF) positively and indirectly influences TANePS adoption in the public sector.

$\mathrm{H}_{2 \mathrm{a}}$ : Performance expectancy (PE) positively and directly influences TANePS adoption in the public sector

$\mathrm{H}_{2 \mathrm{~b}}$ : In the presence of Relative Advantage (RA), Performance Expectancy (PE) positively and indirectly influences TANePS adoption in the public sector. 
$\mathrm{H}_{2 \mathrm{c}}$ : In the presence of Attitude (AT), Performance Expectancy (PE) positively and indirectly influences TANePS adoption in the public sector.

$\mathrm{H}_{3 \mathrm{a}}$ : Relative advantage (RA) positively and directly influences TANePS adoption in the public sector

$\mathrm{H}_{3 \mathrm{~b}}$ : In the presence of Attitude (AT) Relative advantage (RA) positively and indirectly influences TANePS adoption in the public sector

$\mathrm{H}_{4}$ : Attitude (AT) positively and directly influences TANePS adoption in the public sector.

Table 1.

Summary of Hypotheses Generated from the Theoretical Model

\begin{tabular}{|c|c|c|c|}
\hline Hypothesis & Path & & Influence \\
\hline $\mathrm{H} 1_{\mathrm{a}}$ & LF $\rightarrow$ TA & $\rightarrow \mathrm{H}_{1}$ & Direct \\
\hline $\mathrm{H} 1_{\mathrm{b}}$ & LF->PE $->$ TA & $\rightarrow \mathrm{H}_{2} \cdot \mathrm{H}_{5}$ & Indirect \\
\hline $\mathrm{H} 1_{\mathrm{c}}$ & LF-> RA -> TA & $->\mathrm{H}_{3} \cdot \mathrm{H}_{8}$ & Indirect \\
\hline $\mathrm{H} 1_{\mathrm{d}}$ & LF $->$ AT-> TA & $->\mathrm{H}_{4} \cdot \mathrm{H}_{10}$ & Indirect \\
\hline $\mathrm{H} 2_{\mathrm{a}}$ & PE->TA & $\rightarrow \mathrm{H}_{5}$ & Direct \\
\hline $\mathrm{H} 2_{b}$ & PE $->\mathrm{RA}->\mathrm{TA}$ & $\rightarrow \mathrm{H}_{6} \cdot \mathrm{H}_{8}$ & Indirect \\
\hline $\mathrm{H} 2_{\mathrm{c}}$ & $\mathrm{PE}-->\mathrm{AT} \rightarrow \mathrm{TA}$ & $->\mathrm{H}_{7} \cdot \mathrm{H}_{10}$ & Indirect \\
\hline $\mathrm{H} 3_{\mathrm{a}}$ & RA $->$ TA & $->\mathrm{H}_{8}$ & Direct \\
\hline $\mathrm{H} 3_{\mathrm{b}}$ & RA $->$ AT $->$ TA & $->\mathrm{H}_{9} \cdot \mathrm{H}_{10}$ & Indirect \\
\hline $\mathrm{H} 4$ & AT $->$ TA & $->\mathrm{H}_{10}$ & Direct \\
\hline
\end{tabular}

Key: LF=Legal Framework; PE= Performance Expectancy; RA=Relative Advantage; AT= Attitude and $\mathrm{TA}=\mathrm{TANePS}$ Adoption

\section{Methods}

2.1 Philosophy, Research Design, Data Collection Methods, Target Population and Sample Size

This study adopted positivism philosophy and cross-sectional survey research design. The study also used purposive and stratified sampling techniques. Sample size was 157 respondents of whom 100 were trained procurement experts from the selected procuring entities for piloting TANePS adoption and 57 were trained and registered suppliers in TANePS. A questionnaire with closed ended questions and documentary review were used for data collection. The collected data were analysed using descriptive statistics with the help of Statistical Package for Social Sciences software Version 21 and Partial Least Squares Structural Equation Modelling with the help of SmartPLS 3 software.

The study was conducted in Tanzania because of the initiatives shown of improving the public procurement systems which led to piloting TANePS adoption in procuring entities based in Arusha, Dar es Salaam, Dodoma, Mbeya and Mwanza (URT, 2018). Therefore, the study was conducted in those five cities of Tanzania because suppliers and procurement experts working with selected procuring entities were trained on how to use and interact with TANePS.

The unit of analysis were registered suppliers in TANePS and procurement experts from each selected procuring entity who attended training for piloting TANePS adoption (URT, 2018). The registered suppliers in TANePS and procurement experts were used because they were the ones who were trained on how to interact with the system in the course of acquiring goods and were regarded to have the required knowledge and skills pertaining operationalization of TANePS in the country. Therefore, the targeted population was 987 of whom 730 were suppliers who were trained and registered in TANePS and 257 were procurement experts who were trained with regard to TANePS application (URT, 2019). The sample size was obtained using Yamane formula (Magigi, 2015) given by: $n=N /\left(1+N\left(\right.\right.$ e) $\left.{ }^{2}\right)$ Where $n=$ the required sample, $\mathrm{N}=$ Target Population, e=Level of Precision assuming a 95\% confidence level and precision of $\pm 5 \%$, Given $\mathrm{N}=987$ (URT, 2018) then expected sample size was 285 
(approximated). However, the total actual sample size obtained in data collection for this study was 157 (55.09\% of expected sample size) from which 35.09 per cent of the respondents were from procuring entities and 20 per cent of the respondents were suppliers.

Generally, this response rate was good and representable and conforms to Mugenda (2003) who stipulated that a response rate of $50 \%$ is adequate for analysis, a response rate of $60 \%$ is good and a response rate of $70 \%$ and over is excellent. In addition, this study was able to achieve higher statistical powers with unexpected sample size because the actual sample size collected was more than the minimum number of sample size required for this study under the rule of thumb suggested by Hair et al. (2014) which requires number of indicators of the exogenous latent construct (with maximum indicators) times ten equals to be the minimum number of the sample size for the research model to be tested its hypotheses. Taking into consideration the number of indicators of legal framework as exogenous latent construct of the research model times ten equals to forty (40).

\subsection{Data Processing and Analysis}

Questionnaire with closed ended questions were assigned numbers to enable the process of quantitative data analysis be more accurate and simpler. All missing values were assigned 99 as special number before executing the PLS algorithm and bootstrapping. In data analysis for this study, the PLS-SEM evaluation procedures were used for reflective models suggested by Sartedt et al. (2014) cited in Sartedt et al., 2017. Basing on PLS-SEM evaluation procedures for reflective model suggested by Sartedt et al. (2014) cited in Sartedt et al., 2017, the analysis was performed by assessing reflective measurement models and structural models. This study adopted PLS-SEM evaluation procedures for reflective models due to the nature of the constructs and their indicators in the theoritical model as suggested by Hair et al. (2018). All indicators depended on their constructs hence, reflective model was an appropriate for this study.

\section{Results}

\section{1 $R^{2}$ Value of the Endogenous Constructs and Relevance of the Path Coefficients}

Figure 2 indicates $\mathrm{R}^{2}$ values which measured the variance explained by the exogeneous construct in each of the endogenous construct. In this study, 53.3 per cent of the variation of attitude (AT) was influenced by legal framework (LF), performance expectancy (PE) and relative advantage (RA). These results meant that attitude is a link of others critical success factors influencing TANePS adoption. Above all, Figure 2 shows the relevance of the path coefficients of the research model. In this study, the path coefficient of the hypothesized relationship of attitude and TANePS adoption was positive which meant that an increase in one standard deviation of the attitude translated into increase of the rate of TANePS adoption by 57.7 per cent. 


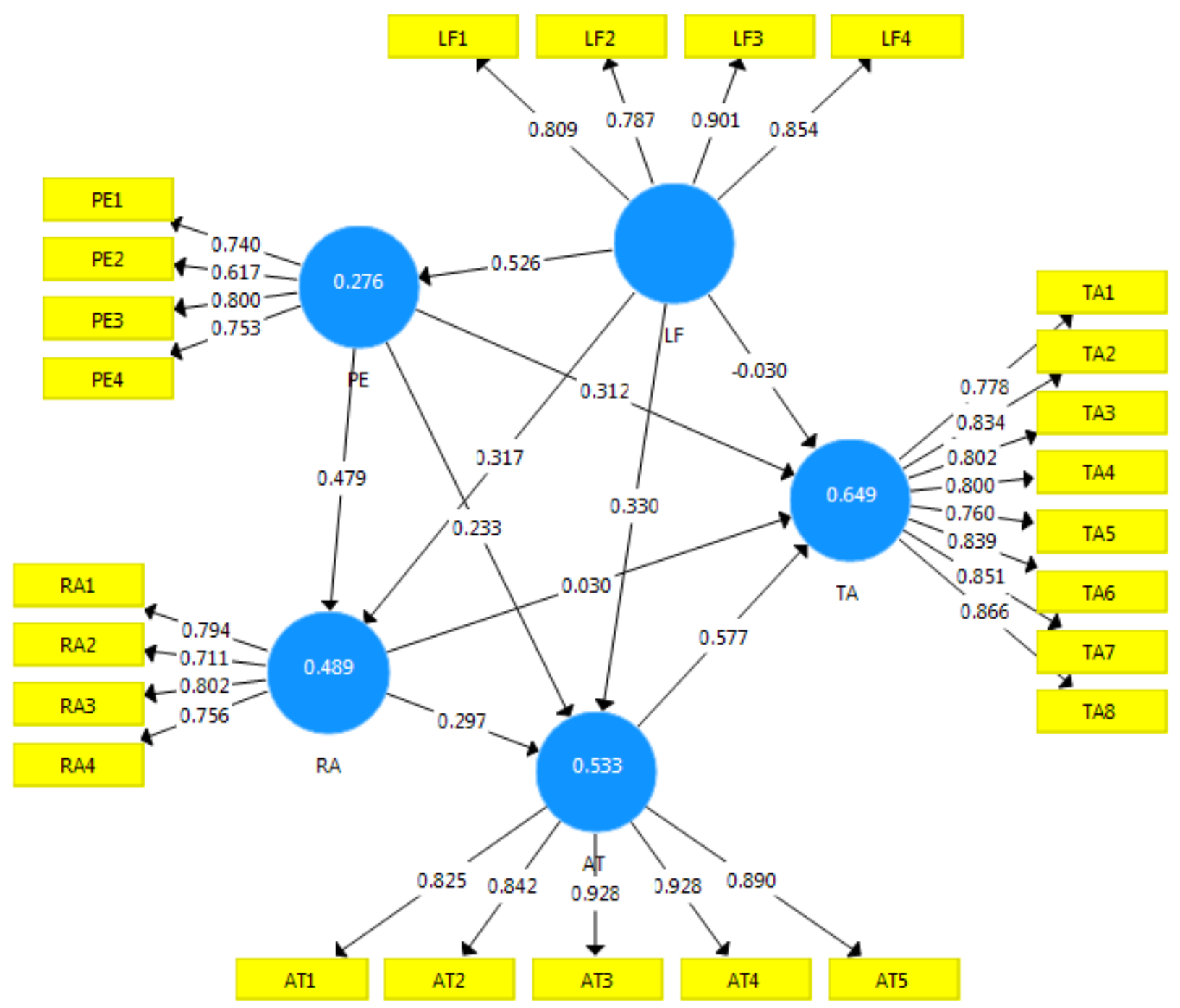

Key:LF=Legal Framework; PE= Performance Expectancy; RA=Relative Advantage; AT= Attitude and $\mathrm{TA}=\mathrm{TANePS}$ Adoption

Figure 2. $\mathrm{R}^{2}$ Value of the Endogenous Constructs and Relevance of the Path Coefficients

\subsection{Statistical Significance Testing of the Hypothesized Relationships}

The results in figure 3 show that all hypothesized relationships towards attitude from legal framework (LF), performance expectancy (PE) and relative advantage (RA) were accepted indicating that the hypothesized relationships appeared to exist in real life and changing the attitude of buyers and suppliers is the most important aspect towards e-procurement adoption in public sector. 


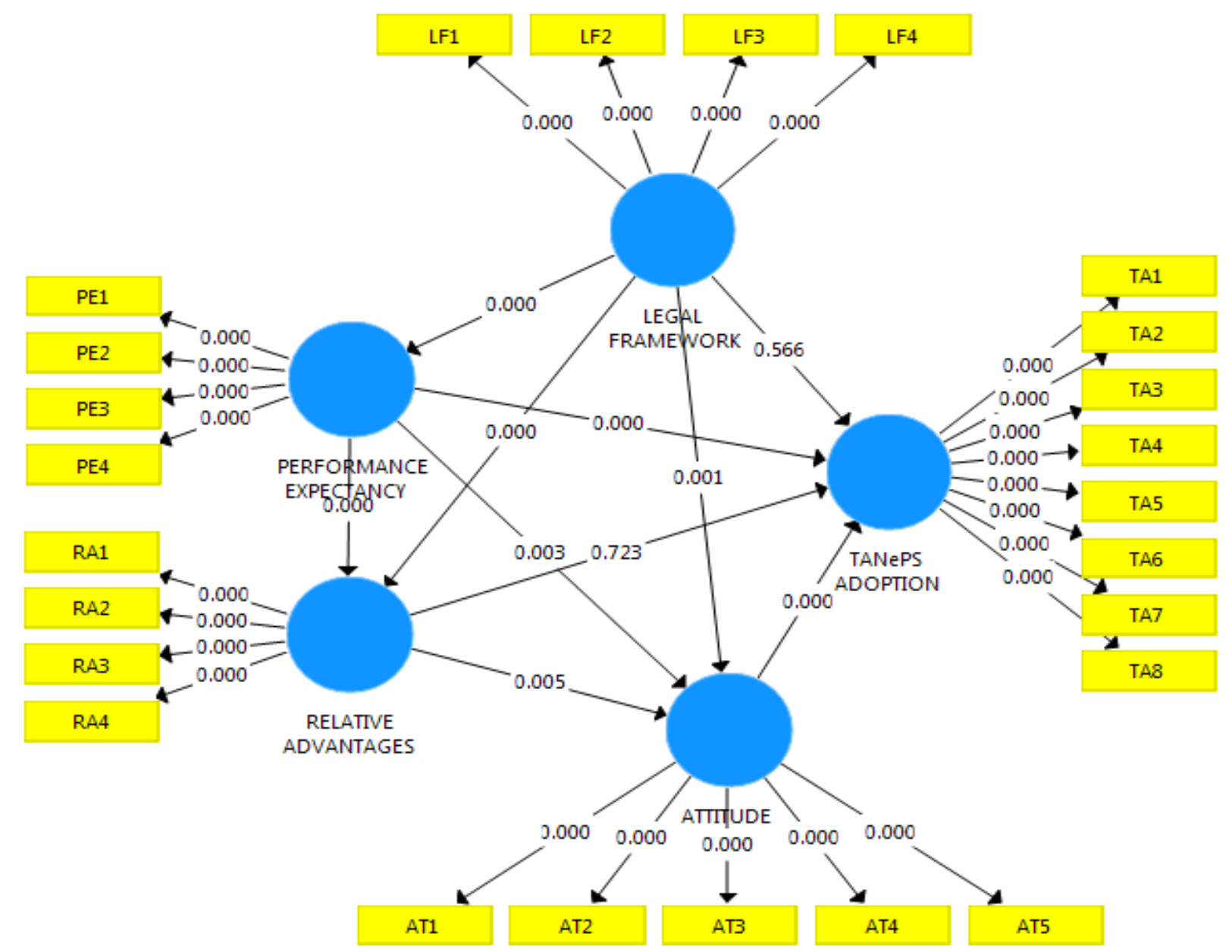

Figure 3. Statistical Significance of the Hypothesized Relationships

Table 2.

Findings of Hypotheses Tested from the Theoretical Model

\begin{tabular}{lllcl}
\hline Hypothesis & Path & Influence & P-value & Remark \\
\hline $\mathrm{H} 1_{\mathrm{a}}$ & LF -> TA & Direct & 0.566 & Rejected \\
$\mathrm{H} 1 \mathrm{~b}$ & LF->PE -> TA & Indirect & 0.000 & Accepted \\
$\mathrm{H} 1 \mathrm{c}$ & LF-> RA -> TA & Indirect & 0.000 & Accepted \\
$\mathrm{H} 1 \mathrm{~d}$ & LF - $\mathrm{AT}->$ TA & Indirect & 0.000 & Accepted \\
$\mathrm{H} 2_{\mathrm{a}}$ & PE->TA & Direct & 0.000 & Accepted \\
$\mathrm{H} 2_{\mathrm{b}}$ & PE -> RA -> TA & Indirect & 0.000 & Accepted \\
$\mathrm{H} 2_{\mathrm{c}}$ & PE -> AT -> TA & Indirect & 0.000 & Accepted \\
$\mathrm{H} 3_{\mathrm{a}}$ & RA -> TA & Direct & 0.723 & Rejected \\
$\mathrm{H} 3_{\mathrm{b}}$ & RA $>$ AT-> TA & Indirect & 0.000 & Accepted \\
$\mathrm{H} 4$ & AT-> TA & Direct & 0.000 & Accepted \\
\hline
\end{tabular}

Key: LF=Legal Framework; PE= Performance Expectancy; RA=Relative Advantage; AT= Attitude and $\mathrm{TA}=\mathrm{TANePS}$ Adoption

\section{Discussion}

\subsection{Influences of Hypothesized Critical Success Factors Towards TANePS Adoption}

In this study legal framework was postulated to positively and directly influence TANePS adoption in public sector. The findings revealed negative path coefficient which meant that an increase in one standard deviation of the legal framework translated into decrease of the rate 
of TANePS adoption and it was found statistically insignificant (because p-value was $>0.05$ ) implying that, the relationship does not exist in real life hence, this direct relationship does not influence procurement experts' and suppliers' decisions to adopt and use TANePS.

On the other hand, legal framework was postulated to positively and indirectly influence TANePS adoption in public sector through performance expectancy, relative advantage and attitude. The findings revealed positive path coefficients which meant that an increase in one standard deviation of the legal framework translated into increase of the rate of TANePS adoption and it was found statistically very significant ( $\mathrm{p}$-value was $<0.05$ ) which meant the indirect relationships exist in real life. These findings are similar to the previous studies like the studies by Azanlerigu and Akay (2015) and Masele (2014) who found that the relationship was very significant because p-value was less than 0.05 . The study by Masele (2014) proved beyond reasonable doubt that coercive pressures (legal frameworks) are inevitable if commitment towards adoption of new technology was to be instructed for serving public benefits.

However, performance expectancy was postulated to positively, directly and indirectly influence TANePS adoption in public sector. The findings revealed positive path coefficients which meant that an increase in one standard deviation of the performance expectancy translated into increase of the rate of TANePS adoption and it was found statistically significant (p-value < 0.05) which meant that the relationships exist in real life. For performance expectancy being significant in both direct and indirect relationships suggested that procurement experts and suppliers only rely on performance expectancy in order to adopt and use TANePS, hence this factor influences directly and indirectly procurement experts' and suppliers' decisions to adopt and use the new public procurement system. The findings of this study differ from some previous studies for example the study by Taluka (2016) revealed that performance expectance (PE) was positive but statistically insignificant $[\beta=0.069, p=0.443]$ at $\alpha=0.05$, which meant that an increase in one standard deviation in performance expectance translates into 0.069 increase in Behavioral Intention to use Mobile Payment services (BI) for the complete model. In addition, the study by Masele (2014) found insignificant influence of performance expectancy on green e-business adoption due to the fact that the p-value was greater than 0.05 , while the path coefficient was less than 0.2 , implied that, it was less important for discussion.

Relative advantage was also postulated to positively, directly and indirectly influence TANePS adoption in public sector. The findings revealed positive path coefficient for the direct influence which meant that an increase in one standard deviation of relative advantage translated into increase of the rate of TANePS adoption but the relationship was found statistically insignificant because p-value was $>0.05$ which implied the relationship does not exist in real life. For relative advantage being insignificant could suggest that procurement experts and suppliers do not only rely on relative advantage of TANePS in order to adopt and use the system, hence factor does not influence procurement experts' and suppliers' decisions to adopt the system. This fact also meant that understanding of the advantages of new technology alone without change of mindset (attitude) does not influence stakeholders' decisions to adopt the new technology. On the other hand, relative advantage was postulated to positively and indirectly influence TANePS adoption in public sector. The findings revealed positive path coefficient which meant that an increase in one standard deviation of relative advantage translated into increase of the rate of TANePS adoption and it was found statistically significant ( $\mathrm{p}$-value $<0.05)$ which meant the relationship exists in real life. These findings correspond to the previous studies' findings for example the study by Ibem et al. (2016) revealed that the perceived benefits of e-procurement were the reason why most organizations in the construction industry use it in Nigeria. 


\subsection{Influence and Linkage of Attitude Towards TANePS Adoption}

Above all, attitude was postulated to positively and directly influence TANePS adoption in public sector. The findings revealed positive path coefficient which meant that an increase in one standard deviation of the attitude translated into increase of the rate of TANePS adoption and it was found statistically significant ( $\mathrm{p}$-value $<0.05$ ) which meant that the relationship exists in real life. For attitude being significant in direct relationship and mediates other critical success factors legal framework, performance expectancy and relative advantage suggested that procurement experts and suppliers only rely on change of their attitude in order to adopt and use TANePS, hence this factor influences directly procurement experts' and suppliers' decisions to adopt and use the new procurement system. These findings are similar to the findings of the study by Kassim and Hussin (2013) revealed that user attitude has always been found to have a strong, direct and positive effect with behaviour and there is link between attitude and behavior. However, user attitude is the fundamental in attitudinal research and has been supported in a wide variety of settings. In addition, Kassim and Hussin (2013) assert that the attitude is still significant in determining the public e-procurement system use among the agencies and this can be clarified by feelings of the top management as one of the users, and the perceptions from other users on the system like suppliers that are accumulated to form a cumulative decision that either accelerate or hold up the use decision (Kassim \&Hussin, 2013). Although these findings are similar with some other studies on technology adoption for public benefits, the TOE postulated top management attitude as part of organizational factor which influences new technologies adoption in public sector. Therefore, this study has contributed new knowledge with regard to the influence of attitude on new technology (TANePS) adoption in two perspective; public and private sector of which the existing theories and empirical studies are informative indecisively. The critical success factor "attitude" from TOE model to influence and links legal framework, performance expectancy and relative advantage in the process of adopting new technology for public and private gains is considerable missing in the current literature because studies which focus on buyer-supplier perspectives with indirect relationships of the critical success factors influencing e-procurement adoption are currently insufficient.

\section{Conclusion}

The final theoretical model of this study has accommodated determinants from UTAUT and TOE which are valid to buyers'-suppliers' perspectives. Additionally, the theoretical model is valid when researchers use a method for data analysis which accommodates direct and indirect relationships like PLS-SEM with the help of SmartPLS 3 software. However, validity of this theoretical model is not limited to the geographical area in the world hence it can be used in any developing country to conduct researches related to e-procurement adoption in public sector because of the similarities of the public procurement procedures in the world. Figure 4 shows the final model of this study 

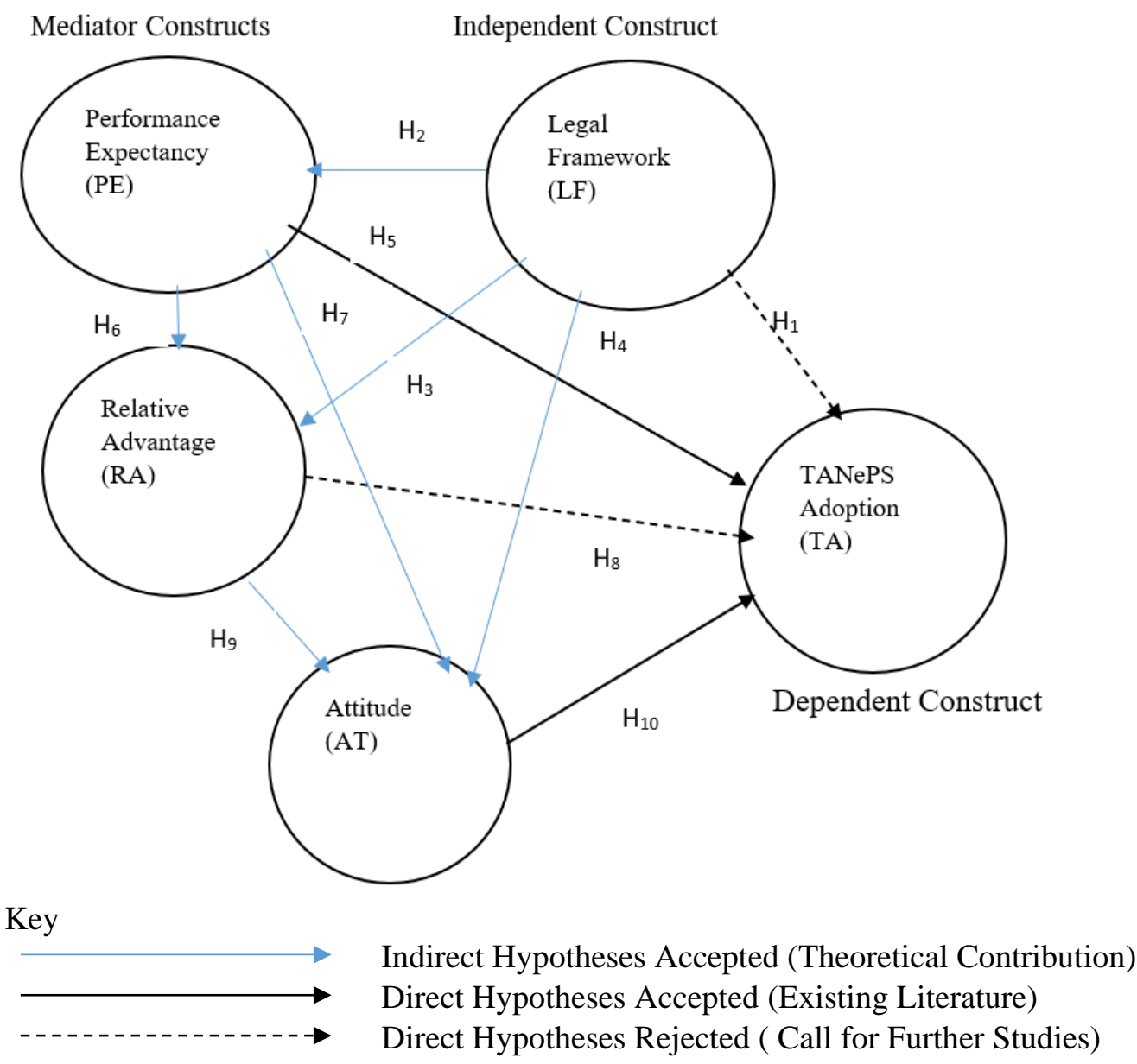

Figure 4. Final Model for TANePS Implementation. Source: Validated the Conceptualized Model from Literature, 2020

\section{Recommendations of The Study}

Basing on the findings and final integrated theoretical model of this study, the Government of Tanzania should ensure that the benefits, performance expectancy and the legal framework supporting TANePS adoption are realized by all parties involved in order to significant change the mindset of all stakeholders. Lastly, the theorical model of this study is recommended to be tested to other developing countries to see its applicability and if it can be generalized for eprocurement adoption in public sector.

\section{Acknowledgments}

The researchers wish to acknowledge Prof. Joseph Hair and Prof. Christian Ringle for their facilitations on quantitative data analysis workshop conducted at University of Dar es Salaam Business School in Tanzania. All facilitators enabled the researchers to acquire knowledge and skills of which they have used to analyze the data and write this paper.

\section{References}

Azanlerigu, J.A. \& Akay, E. (2015). Prospects and challenges of e-procurement in some selected public institutions in Ghana. European Journal of Business and Management, 7 (29). 
Basheka, C. B., Oluka, N. P. \&Mugurusi, G. (2012). Adopting new approaches for public procurement efficiency: critical success factors (CSFS) for the implementation of eprocurement in Uganda's public sector. International Journal of Procurement Management, $5(6)$.

Hair, J. F., Ringle, C. M. \& Sarstedt, M. (2014). PLS-SEM: Indeed, a silver bullet. The Journal of Marketing Theory and Practice, 19 (2), 139-152.

Hair, J.F., Risher, J.J., Sarstedt, M. \& Ringle, C.M. (2018). When to use and how to report the results of PLS-SEM. European Business Review, Permanent link to this document: https://doi.org/10.1108/EBR-11-2018-0203

Ibem, E.O., Aduwo, E.B., Tunji-Olayeni, P., Ayo-Vaughan, E.K. \& Uwakonye, O.U. (2016). Factors influencing e-procurement adoption in the Nigerian building industry. Journal of Construction Economics and Building, 16 (4), 54-67.

Iles, J. (2017). How is e-procurement related to the success of U.S. Cities' Sustainable Purchasing Policies? Arizona State University, ASU School of Sustainability

Jeptoo, N. \& Karanja, K. (2017). Effect of governance structure on e-procurement implementation by state corporations in Kenya. International Academic Journal of Procurement and Supply Chain Management, 2(3), 76-91

Kassim, E. S. \& Hussin, H. (2013). A success model for the Malaysian Government eprocurement system: the buyer perspective. International Journal of Electronic Government Research (IJEGR), 9(1).

Latif, F. B. (2014). The Adoption of Electronic Procurement in Turkey. Advances in Economics and Business, 2 (2), 85-91.

Magigi, W. (2015). Research Proposal Development and Report Writing, Pathway for Success

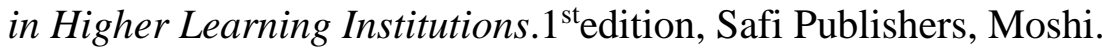

Malekia, D. (2018). E-Procurement as anti-corruption tool in public procurement in Tanzania. European Journal of Business and Management, 7 (14).

Masele, J. J. (2014). Adoption of green e-business applications for sustainable tourism development in developing countries the case of Tanzania. A Thesis Submitted to the Department of Business Informatics I, VLBA-University of Oldenburg in Partial Fulfilment of the Requirements for the Award of Degree of Doctor of Philosophy

Mgidlana, L.M. (2013). Factors affecting the adoption of e-procurement technologies from the supplier perspective. A Research Project Submitted to the Gordon Institute of Business Science, University of Pretoria in Preliminary Fulfilment of the requirement for the Degree of Masters of Business Administration

Mose, J. M., Njihia, J. M. \& Magutu, P. O. (2013). The critical success factors and challenges in e-procurement adoption among large scale manufacturing firms in Nairobi, Kenya. European Scientific Journal 9 (13), 1857- 7431

Mugenda, O. M. (2003). Research methods: Quantitative and Qualitative approaches: African Center for Technology Studies Press, Nairobi:

Mujtaba, B. G. (2014). Managerial Skills and Practices for Global Leadership. ILEAD Academy, Florida.

Ombat, K. O. (2015). Relationship between e-procurement systems and performance of procurement function in commercial banks in Kenya. International Journal of Economics, Commerce and Management, United Kingdom, 3 (12). 
Sarstedt, M., Ringle, C. M. \& Hair, J. F. (2017). Partial Least Squares Structural Equation Modeling, DOI: 10.1007/978-3-319-05542-8_15-1

Schooner, L. S., Gordon, I. D. \& Clark, L. J. (2008). "Public Procurement Systems: Unpacking Stakeholder Aspirations and Expectations". GW Law Faculty Publications and Other Works, 111

Shale, N. I. (2014). Role of e-procurement strategy on the performance of state corporations in Kenya. A Thesis Submitted to the School of Entrepreneurship and Procurement Management in the College of Human Resource Development in Partial fulfilment of the Requirements for the Award of Degree of Doctor of Philosophy in Business Administration (Procurement and Supply Chain Management) of Jomo Kenyatta University of Agriculture and Technology

Shilla, P. (2019). Highlights of "Tanzania National e-Procurement System" paper presented in the $12^{\text {th }}$ East African Public Procurement Forum held in Arusha-Tanzania.

Suleiman, M. (2015). Adoption of e-procurement and value addition: Tanzanian context. European Journal of Business and Management, 7(14).

Taluka, E.A. (2016). Understanding factors influencing consumer behavioral intention to use mobile payment services in rural Tanzania: A Case of Pwani Region. A Dissertation Submitted in Partial Fulfilment of the Requirements for the Degree of Master of Business Administration (MBA) of the University of Dar es Salaam

United Republic of Tanzania (2019). Public Procurement Regulatory Authority Annual performance evaluation report for 2018/2019 financial year

United Republic of Tanzania (2018). Public Procurement Regulatory Authority Annual performance evaluation report for 2017/2018 financial year

United Republic of Tanzania (2016). National Information and Communications Technology Policy, Government Printers, Dar es Salaam.

Watuleke, J. (2017). E-procurement: evolution and adoption. a review of literature, IJRDOJournal of Educational Research: 2456-2947. 